https://doi.org/10.48009/2_iis_2006_14-17

\title{
TOWARD A UNIFIED ENTERPRISE ARCHITECTURE FRAMEWORK: AN ANALYTICAL EVALUATION
}

\author{
Richard V. McCarthy, Quinnipiac University, richard.mccarthy@quinnipiac.edu
}

\begin{abstract}
Enterprise Architecture is a fairly new concept that has been adopted by large organizations for legal, economic and strategic reasons. It has become a critical component of an overall IT governance program to provide structure and documentation to describe the business processes, information flows, technical infrastructure and organizational management of an information technology organization. Many different enterprise architecture frameworks have begun to emerge over the past 10 years. Three of the most widely used enterprise architecture frameworks are described, and the implications of moving toward a single unified enterprise architecture framework is presented.
\end{abstract}

Keywords: Enterprise Architecture, Department of Defense Architecture Framework, DoDAF, Federal Enterprise Architecture Framework, FEAF, Zachman Framework

\section{INTRODUCTION}

Information technology architectures have become increasingly complex. At the same time, they have taken on a much greater importance, as the need to demonstrate that an organization has a comprehensive governance plan in place has become such a critical success factor. A comprehensive enterprise architecture framework, therefore, has moved from what was once background documentation into a mission-critical component of an organization. What then is an enterprise architecture framework?

Schekkerman [9] defines enterprise architecture as "a complete expression of the enterprise; a master plan which 'acts as a collaboration force' between aspects of business planning such as goals, visions, strategies and Goverence principles, aspects of business operations such as business terms, organization structures, processes and data, aspects of automation such as information systems and databases; and the enabling technological infrastructure of the business such as computers, operating systems and networks."

Bernard [1] defines enterprise architecture as a management program and a documentation method that are combined to perform an actionable and coordinated view of the enterprise strategy, business processes, resource utilization and information flow.

The Federal Enterprise Architecture Framework (FEAF) [2] defines an enterprise architecture as " a strategic information asset base, which defines the mission, the information necessary to perform the mission and the technologies necessary to perform the mission, and the transitional processes for implementing new technologies in response to the changing mission needs. Enterprise architecture includes a baseline architecture, target architecture, and a sequencing plan."

Enterprise architecture is implemented through the use of enterprise architecture frameworks. Several different frameworks exist, for which some are considered general purpose while others are highly specialized.

Though no single universal definition for enterprise architecture has been adopted, key components emerge. Lankhorst [4] described a layered approach to enterprise architecture that identified the following:

1. Business Layer that consists of the products and services that are support the business processes that provide products and services to customers.

2. Application Layer that supports the business layer with services that are utilized by software applications.

3. Technical Layer that provides the infrastructure support and communication services to run applications.

Enterprise architecture at a minimum addresses the complex relationships between the business, information and technical layers of an organizations information technology applications and infrastructure.

Enterprise architecture is therefore different from a system design methodology. Enterprise architecture is used for the following:

- To generate make-buy decisions

- To discriminate between options 
- To discover business requirements

- To drive systems to a common purpose

Weill and Ross [10] demonstrated that enterprise architecture is a critical component of an IT governance program and that effective governance aligns IT investments with business priorities. Further, in a survey of 300 companies worldwide, they concluded that there was a correlation between superior governance and superior financial results. This suggests that enterprise architecture is one of the critical strategic drivers in place within an information technology organization.

Each of these definitions points to the comprehensive scope of enterprise architecture and that a critical component is the need for comprehensive documentation.

We discuss the importance of enterprise architecture and describe three of the best known enterprise architecture frameworks in use. We conclude with an analysis of the potential to move towards a unified enterprise architecture framework.

\section{THE IMPORTANCE OF ENTERPRISE ARCHITECTURE}

Schekkerman [9] surveyed 79 companies that are interested in enterprise architecture use. The results suggest that the greatest interest in enterprise architecture is due to its use in supporting strategic information technology issues and decisions within an organization. The highest responses included using enterprise architecture as a road map for change, utilizing it to help manage the IT portfolio or support budget prioritization and to support decision making.

\section{Essential Enterprise Architecture Framework Components}

Though numerous different enterprise architecture frameworks exist; there are essential components that each framework addresses directly or indirectly. These include the following:

1. Alignment - providing a framework to enable better alignment of business and information technology objectives. The architecture used can also serve as a communication tool.

2. Integration - establishing a infrastructure that enables business rules to be consistently applied across the organization, documents data flows, uses and interfaces.

3. Value Creation - the economic value of information technology is better measured in an environment where there is a higher potential for reusable hardware and software assets.

4. Change Management - establishing a consistent infrastructure and formalizing the management of the infrastructure and information assets better enables an organization-wide change management process to be established to handle information technology changes.

5. Compliance - enterprise architecture provides the artifacts necessary to ensure legal and regulatory compliance for the technical infrastructure and environment.

\section{ENTERPRISE ARCHITECTURE FRAMEWORKS}

There are several standard enterprise architecture frameworks. Many companies that have become interested in implementing a standard framework have also taken the approach of customizing an existing framework to meet their needs. The most commonly used enterprise architecture frameworks include the Zachman Framework, the Department of Defense Architecture Framework (DoDAF), the US Federal Enterprise Architecture Framework (FEAF), the Open Group Architecture Framework (TOGAF) and the Extended Enterprise Architecture Framework (E2AF) [9].

\section{Federal Enterprise Architecture Framework}

The Federal Enterprise Architecture Framework (FEAF) establishes four views of information technology architecture that utilize the first three columns of the Zachman Framework and the Spewak EA Planning Methodology (also referred to as E2AF) [2]. The architecture includes business, data, applications and technology domains that serve as a reference point to guide the efficient flow of information, common business processes and technology across Federal Agencies of the U.S. government. Documentation standards have been developed for each systems domain within the architecture framework (Table1) that address four perspectives (also consistent with the Zachman Framework). These provide a standardized approach to documenting and describing the business, information and technical flows of the complete application portfolio. 
Table 1. Federal Enterprise Architecture Framework Architecture Matrix

\begin{tabular}{|l|l|l|l|}
\hline & Data Architecture & $\begin{array}{l}\text { Applications } \\
\text { Architecture }\end{array}$ & $\begin{array}{l}\text { Technology } \\
\text { Architecture }\end{array}$ \\
\hline Planner Perspective & List of Business Objects & $\begin{array}{l}\text { List of Busienss } \\
\text { Processes }\end{array}$ & $\begin{array}{l}\text { List } \\
\text { Locations }\end{array}$ \\
\hline Owner Perspective & Semantic Model & Business Process Model & $\begin{array}{l}\text { Business } \\
\text { System }\end{array}$ \\
\hline Designer Perspective & Logical Data Model & Application Architecture & $\begin{array}{l}\text { System } \\
\text { Deployment Architecture }\end{array}$ \\
\hline Builder Perspective & Physical Data Model & Systems Design & Technology Architecture \\
Pubcontractor & Data Dictionary & Programs & Network Architecture \\
\hline
\end{tabular}

\section{Department of Defense Architecture Framework}

Perhaps the best known enterprise architecture framework in the United States is the Department of Defense Architecture Framework (DoDAF). The DoDAF consists of four views (all view, system view, operational view and technical standards view) that define a common approach for architecture description, development, presentation, and integration of war-fighting operations and business operations. The DoDAF was created in 2003 to combine the now obsolete C4ISR (command, control, communication, computers and intelligence) framework with components of the Federal Enterprise Architecture Framework model.

The All View provides the overarching support for an organization that defines its scope, architecture plans and definitions. The Systems View describes the system and applications that support mission critical functions. The Operational View focuses on the behaviors and functions that describe the enterprise. Included in the operational view is a definition of the type of information that is exchanged, the frequency of exchange and the tasks and activities that are required to complete each information exchange. The Technical Standards View describes the policies standards and constraints for the infrastructure of an organization.

Each view contains an extensive set of documentation; however, a subset of the entire document set is considered to be the essential core documentation of the framework. This core consists of the following:

- AV-1: Overview and Summary Information

- AV-2: Integrated Dictionary

- OV-2: Operational Node Connectivity Description
- OV-3: Operational Information Exchange Matrix

- OV-5: Operational Activity Model

- SV-1: System Interface Description

- TV-1: Technical Standards Profile

The format of each documentation element is standardized, with much of the documentation utilizing UML to achieve this standardization. [3]

\section{Zachman Framework}

The most widely used of the formal enterprise architecture framework models is the Zachman Framework. Developed in 1987, it seeks to define a logical construct to control the interfaces and components of an information systems environment and provides a standardized method for considering all aspects of an information technology. The framework utilizes a series of cells to describe the information, business and technical flows. These are organized by data, function, network, people, time and motivation that are principally driven by the business requirements of an organization. The framework successfully combines people, data and technology to show a comprehensive view of the inter-relationships within an information technology organization. It is principally driven by business requirements and although some standardized documentation is prescribed (e.g., data dictionary), it does not contain the formalized documentation structure of the Federal Enterprise Architecture Framework or the Department of Defense Architecture Framework models. It does, however, present a formal picture of an entire enterprise from the perspectives of owner, designer and builder. This permits analysis of the information technology environment on the basis of WHO, WHAT, WHEN and WHERE information is used [11]. Neaga and Harding [6] have further described the Zachman Framework as a conceptual methodology that 
describes how all specific architectures could be integrated into a single comprehensive enterprise architecture.

\section{DISCUSSION}

It has only been in the past 10 years that enterprise architecture and the frameworks that support enterprise architecture have gained any significant attention. More recently the need for standardization of processes, documentation and information technology asset control have become an integral component of many organizations overall IT governance plan. The Sarbanes-Oxley Act of 2002 has resulted in a significant impact on information technology organizations to demonstrate that they are effectively controlling the infrastructure and applications that are vital to an organizations success [5]. Although numerous enterprise architecture frameworks have emerged, there appears to be a convergence towards standardization of enterprise architecture frameworks. This evaluation of three of the mostly commonly used enterprise architecture frameworks has revealed that there is more in common with these frameworks than there are differences. Each recognizes the inter-relatedness of information flows, applications and technical infrastructure. Each framework prescribes a specific methodology that addresses business requirements, information flow and technical infrastructure. Each framework also has grown in usage.

This suggests the future potential to move towards a single unified enterprise architecture framework standard. The Unified Modeling Language (UML) plays a significant role. It is the documentation aid for many of the processes and standards that an organization requires to understand and manage its information technology assets more effectively. Richardson, Jackson and Dickson [7] concluded that consensus for underlying architectural principles is critical to the success of architecture. A convergence of enterprise architecture models will continue to be an evolutionary process. Enterprise architecture frameworks go well beyond the networking capabilities of the Internet to expand into information, application and business process management across enterprises.

\section{FUTURE WORK}

This investigation is the beginning of a planned research study in enterprise architecture use and evolution. A future study will be performed to survey organizations that have implemented an enterprise architecture framework to determine their perception of its value, metrics used to measure its value and critical components to successful enterprise architecture implementation.

\section{REFERENCES}

1. Bernard, S. (2004). An Introduction to Enterprise Architecture, Bloomington, IN: AuthorHouse.

2. CIO Council. (2001, February). A Practical Guide to Federal Enterprise Architecture, Version 1.0, Federal Chief Information Officers Council.

3. DoDAF Working Group. (2004, February 9). DoD Architecture Framework 1.0, white paper.

4. Lankhorst, M. (2004). Enterprise architecture modeling: The issue of integration, Advanced Engineering Informatics, 18, 205-216.

5. McCarthy, R. \& Barrett, D. (2005). The impact of the Sarbanes-Oxley Act on information technology: Two perspectives, Proceedings of the International Association of Computer Information Systems Pacific conference, Taipei, Taiwan, May 19-21, 437-442.

6. Neaga, E. \& Harding, J. (2005, March). An enterprise modeling and integration framework based on knowledge discovery and data mining, International Journal of Production Research, 43(6), 1089-1108.

7. Richardson, G., Jackson, B. \& Dickson, G. (1990, Dec.). A principles-based enterprise architecture: Lessons from Texaco and Star Enterprise, MIS Quarterly, 14(4), 385-403.

8. Schekkerman, J. (2004). How to survive in the jungle of Enterprise Architecture Frameworks, Victoria, BC: Trafford.

9. Schekkerman, J. (2005). Trends in Enterprise Architecture, Institute for Enterprise Architecture Development, white paper.

10. Weill, P. \& Ross, J. (2005, Winter), A matrixed approach to designing IT governance, MIT Sloan Management Review, 46(2), 26-34.

11. Zachman, J.A. (1987). A framework for information systems architecture, IBM Systems Journal, 26(3) 276-292. 